\title{
Clinical Study Correlation of DNA Ploidy with Progression of Cervical Cancer
}

\author{
M. Singh, ${ }^{1}$ S. Mehrotra, ${ }^{2}$ N. Kalra, ${ }^{1}$ U. Singh, ${ }^{2}$ and Y. Shukla ${ }^{1}$ \\ ${ }^{1}$ Industrial Toxicology Research Center, P.O. Box 80, M.G. Marg, Lucknow 226001, India \\ ${ }^{2}$ Department of Obstetrics \& Gynecology, Queen Merry Hospital, King George’s Medical University, Lucknow 226003, India
}

Correspondence should be addressed to Y. Shukla, yshukla@itrc.res.in

Received 7 April 2007; Revised 26 July 2007; Accepted 24 November 2007

Recommended by Qingyi Wei

\begin{abstract}
The majority of squamous cell carcinomas of cervix are preceded by visible changes in the cervix, most often detected by cervical smear. As cervical cancer is preceded by long precancerous stages, identification of the high-risk population through detection of DNA ploidy may be of importance in effective management of this disease. Here we attempted to correlate aneuploid DNA patterns and their influence on biological behavior of flow-cytometry analysis of DNA ploidy which was carried out in cytologically diagnosed cases of mild (79), moderate (36), and severe (12) dysplasia, as well as "atypical squamous cells of unknown significance (ASCUS)" (57) along with controls (69), in order to understand its importance in malignant progression of disease. Cytologically diagnosed dysplasias, which were employed for DNA ploidy studies, 39 mild, 28 moderate, and 11 severe dysplasia cases were found to be aneuploid. Out of the 69 control subjects, 6 cases showed aneuploidy pattern and the rest 63 subjects were diploid. An aneuploidy pattern was observed in 8 out of 57 cases of cytologically evaluated ASCUS. The results of the followup studies showed that aberrant DNA content reliably predicts the occurrence of squamous cell carcinoma in cervical smear. Flow cytometric analysis of DNA ploidy may provide a strategic diagnostic tool for early detection of carcinoma cervix. Therefore, it is a concept of an HPV screening with reflex cytology in combination with DNA flow cytometry to detect progressive lesions with the greatest possible sensitivity and specificity.
\end{abstract}

Copyright ( $) 2008$ M. Singh et al. This is an open access article distributed under the Creative Commons Attribution License, which permits unrestricted use, distribution, and reproduction in any medium, provided the original work is properly cited.

\section{INTRODUCTION}

Cervical cancer is the second most common malignancy in women worldwide. It is estimated that, globally, 466,000 new cases of cervical cancer are diagnosed each year. As per estimate 231,000 women in a year die of cervical cancer and $80 \%$ of them are from the developing world [1]. Use of cytological screening technique, Papanicolaou (Pap) test, has significantly increased the detection of cervical cancer [2]. Cancer of cervix emerges from a defined series of preneoplastic lesions with increasing cellular dysplasia, referred to as cervical intraepithelial neoplasia (CIN) grade I, II, and III. However, CIN lesions frequently regress, and not all CIN III lesions, progress to invasive cancer [3]. The group of CIN is very heterogeneous, particularly in their clinical behavior. Persistent infection with highrisk-type human papilloma viruses (HPVs) is the strongest independent risk factor for cervical cancer [4]. CIN lesions induced by HPV infection and genomes of these viruses were detected in the vast majority of cervical cancer specimens
[5-7]. During the course of tumor initiation in an HPVinfected cervical epithelial cell, an aneuploid DNA pattern develops [8], which along with its descendants shows genetic instability. Aneuploidy reflects a situation of uncontrolled increase of DNA and loss of essential information [9] and plays an important role in neoplastic transformation. Increased aneuploid DNA value with the increase in grades of cervical dysplasia has long been considered to be a specific prognostic marker of malignancy [10]. However, at present, no well-established technique, which, qualitatively, predicts the clinical outcome of cervical dysplasia except Pap smear screening, is available. Approximately $15-30 \%$ of all women who developed low-grade squamous intraepithelial lesion (LSIL) have a probability of developing moderateto-severe cervical intraepithelial neoplasia (CIN II and III) identified on a subsequent cervical biopsy [11]. To prevent cervical malignancy and its precursors, several adjuvant diagnostic methods have been proposed to strengthen the accuracy of cytological and histological diagnosis [12]. As chromosomal aneuploidy has been used as an early key event 
in tumorigenesis caused by genetic instability [13, 14], the cytometric equivalence of chromosomal aneuploidy detected by DNA flow-cytometry may serve as a marker of neoplasia and provide valuable information for the diagnosis and understanding of pathogenesis of cervical cancer. Since aneuploid pattern of DNA is a useful parameter for the prediction of progression and persistence of "atypical squamous cells of unknown significance (ASCUS)", low-grade squamous intraepithelial lesion (LSIL/mild dysplasia/CIN I), and highgrade squamous intraepithelial lesion (HSIL/moderate and severe dysplasia/CIN II and III) in clinical practice, the present study was designed to investigate whether alteration in cellular/nuclear content predicts the occurrence of cancer in cervical smears. We have thus estimated their DNA content using flow cytometry and compared it with the cytological findings.

\section{MATERIALS AND METHODS}

\subsection{Subjects and sampling}

The cases were derived from the ongoing outpatient cytology screening at Department Obstetrics and Gynecology, King George's Medical University (Lucknow, India) for the present study. Cytologically diagnosed 127 cases of dysplasia (79 mild, 36 moderate, and 12 severe), 57 cases of "atypical squamous cells of unknown significance (ASCUS)" and 69 controls, which enrolled during the period of 20042006, were recruited from a prospective followup study to understand the biological behavior and the natural history of cervical precancerous lesions. None of the patients had any previous history of CIN or had been treated for CIN. All the control women had normal smears. Age of the subjects ranged from 30 to 75 years.

An experienced gynecologist collected cervical samples with blunt end of Ayer's spatula. Two fresh spatulas were used for each preparation. Smears were fixed in alcohol and stained according to Pap method. The blunt end of the second spatula was transferred into a cryo tube immediately, containing $3 \mathrm{~mL}$ chilled PBS $(7.2 \mathrm{pH})$ and quick frozen at $-20^{\circ} \mathrm{C}$ until further use for flow-cytometric analysis. Patients were followed up by cytological as well as DNA flow cytometric analysis.

\subsection{Criteria for cytological classification}

Cytological screening was performed with conventional Pap staining by trained cytologists. All slides were evaluated according to the criteria of the Bethesda System [15]. Precancerous lesions of the uterine cervix were classified as normal, ASCUS, LSIL (mild dysplasia/CIN grade I), and HSIL (moderate dysplasia/CIN grade II, severe dysplasia/CIN grade III and carcinoma in situ/CIS).

\subsection{Criteria for management of precancerous lesions}

To understand the biological behavior of cervical precancerous lesions, the following criteria were followed. (i) The cases initially diagnosed as LSIL (CIN I) and HSIL (CIN II and III) were made to undergo a second Pap smear test after 30 days.

(ii) Cytological confirmed dysplasia cases were enrolled for the followup with the consent of the patients.

(iii) Cases initially diagnosed as CIN III were subjected to colposcopy directed biopsy on day 30 and were directed to gynecologist for further management. A cytological control examination was done after every 6 and 3 months for LSIL and HSIL subjects, respectively, and were categorized as "returned to normal" (after the morphology normalized); progressed (when presented with higher grade of dysplasia); and with no change (when remained at the same grade of dysplasia). The samples were also tested for the DNA ploidy pattern.

(iv) ASCUS and all aneuploid cases from control group were also followed for a period of one year.

\subsection{Flow-cytometric DNA analysis}

To determine the cellular DNA content, the protocol of Nicoletti et al. was followed [16]. In brief, cells were fixed with chilled ethanol for 30 minutes at $4^{\circ} \mathrm{C}$ temperature. After adding propidium iodide (Sigma-Aldrich, Miss, USA), the mixture was stored in dark for 1 hour at room temperature. Lymphocytes were used for calibration. The maximum permitted coefficient of variation (CV) for calibration was $2 \%$. A total of 15,000 cells were counted in each sample. DNA histogram cell-cycle analysis was performed as described by Rabinovitch [17], using ModFit LT for Mac V2.0 software after excluding debris by using electronic gate. The events in G0-G1, S, and G2-M phases of the cell cycle were counted. Cases were regarded as acceptable for analysis if the CV of the G0-G1 peak was 7.0. Lesions were classified as diploid, tetraploid, or aneuploid. If two distinct G0-G1 peaks were present with a DNA index of $\geq 1.15$ (each containing $\geq 10 \%$ of total cell population), the histogram was considered as aneuploid (DNA content). By convention, the first G0-G1 peak represented the diploid peak. Diploid and tetraploid lesions were classified as nonaneuploid. Histogram patterns were termed diploid if there was a single G0-G1 peak. A histogram was classified as tetraploid only if a large peak observed in G2-M (DNA index of 1.80-2.2), containing $\geq 20 \%$ of the total curve and was also associated with a corresponding $8 \mathrm{~N}$ peak.

\subsection{Statistical analysis}

EPI-INFO software was used for calculating the odd ratio and $\chi^{2}$ (chi-square) values. A $P$-value of .05 or less was considered statistically significant $(95 \% \mathrm{CI})$.

\section{RESULTS}

The cervical smears were divided into four groups (see Figure 1). The first group qualified as normal and grouped 69 cases. The second group (57 cases) qualified as ASCUS. 


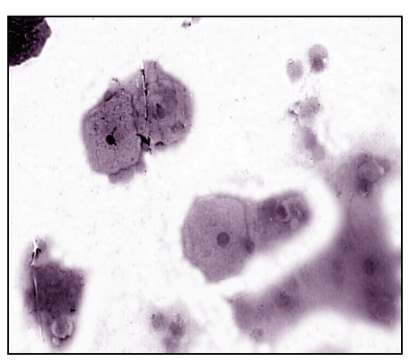

(a)

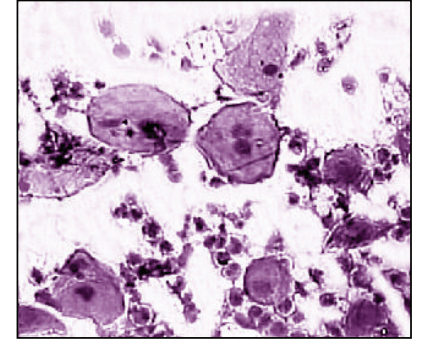

(b)

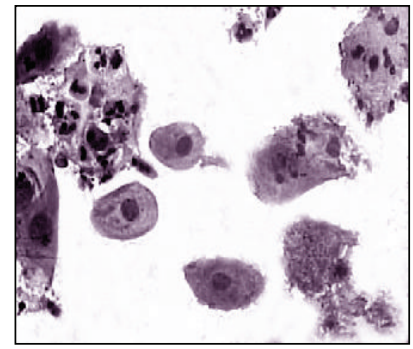

(c)

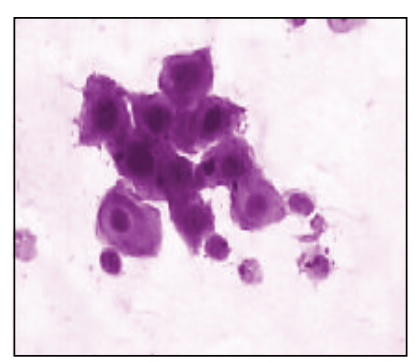

(d)

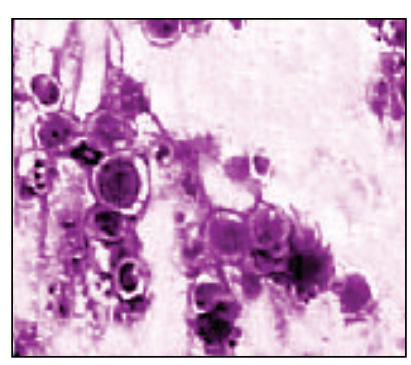

(e)

FIGURE 1: Showing representative cytological images of cervical smears stained according to Pap staining method (magnification: 40X): (a) showing cells with normal morphology, (b) showing "atypical squamous cells of unknown significance," (c) showing cells of mild dysplasia (LSIL/CIN I), (d) showing cells of moderate dysplasia (HSIL/CIN II), (e) showing cells of severe dysplasia (HSIL/CIN III). LSIL: low-grade squamous intraepithelial lesion; HSIL: high-grade squamous intraepithelial lesion; CIN: cervical intraepithelial neoplasia.

TABLE 1: DNA ploidy pattern in control, ASCUS, and various grades of dysplasia cases.

\begin{tabular}{|c|c|c|c|c|c|c|c|c|c|}
\hline $\begin{array}{l}\text { DNA } \\
\text { ploidy }(n)\end{array}$ & $\begin{array}{l}\text { Control } \\
n(\%)\end{array}$ & $\begin{array}{l}\text { ASCUS } \\
n(\%)\end{array}$ & $\begin{array}{l}\text { OR } \\
(95 \% \mathrm{CI})\end{array}$ & $\begin{array}{l}\text { Mild } \\
\text { dysplasia } \\
n(\%)\end{array}$ & $\begin{array}{l}\text { OR } \\
(95 \% \mathrm{CI})\end{array}$ & $\begin{array}{l}\text { Moderate } \\
\text { dysplasia } \\
n(\%)\end{array}$ & $\begin{array}{l}\text { OR } \\
(95 \% \mathrm{CI})\end{array}$ & $\begin{array}{l}\text { Severe } \\
\text { dysplasia } \\
n(\%)\end{array}$ & $\begin{array}{l}\text { OR } \\
(95 \% \mathrm{CI})\end{array}$ \\
\hline $\begin{array}{l}\text { Aneuploidy } \\
(92)\end{array}$ & $\begin{array}{c}6 \\
(8.69 \%)\end{array}$ & $\begin{array}{c}8 \\
(14.03 \%)\end{array}$ & $\begin{array}{c}1.71^{\mathrm{NS}} \\
(0.47-6.26)\end{array}$ & $\begin{array}{c}39 \\
(49.36 \%)\end{array}$ & $\begin{array}{c}10.2^{*} \\
(3.71-29.7)\end{array}$ & $\begin{array}{c}28 \\
(77.77 \%)\end{array}$ & $\begin{array}{c}36.75^{*} \\
(10.35-140.74)\end{array}$ & $\begin{array}{c}11 \\
(91.66 \%)\end{array}$ & $\begin{array}{c}115.50^{*} \\
(11.75-5041.27)\end{array}$ \\
\hline $\begin{array}{l}\text { Diploidy } \\
(161)\end{array}$ & $\begin{array}{c}63 \\
(91.03 \%) \\
\end{array}$ & $\begin{array}{c}49 \\
(85.96 \%) \\
\end{array}$ & 1.00 & $\begin{array}{c}40 \\
(50.36 \%) \\
\end{array}$ & 1.00 & $\begin{array}{c}8 \\
(22.22 \%) \\
\end{array}$ & 1.00 & $\begin{array}{c}1 \\
(8.33 \%)\end{array}$ & 1.00 \\
\hline Total (253) & 69 & 57 & & 79 & & 36 & & 12 & \\
\hline
\end{tabular}

Odd ratios (OR) were computed considering control cases as the base line category for the ASCUS and dysplasia groups.

Not significant ${ }^{\mathrm{NS}} P \geq .05$, Statically significant ${ }^{*} P \leq .001, n$ : Number of cases.

The third and fourth groups comprised of LSIL (79 cases) and HSIL (48 cases; 36 cases in moderate dysplasia and 12 cases in severe dysplasia).

A comparison of DNA content analysis with behavior of LSIL or HSIL in patients having cytologically diagnosed various grades of dysplasia along with the control and ASCUS groups were made (Table 1). 127 cases of different grades of dysplasia were employed for analysis of DNA ploidy out of which 78 (62.99\%) cases were aneuploid (39 mild, 28 moderate, and 11 cases of severe dysplasia) and remaining $49(37.01 \%)$ cases (40 mild, 8 moderate, and 1 severe) were nonaneuploid, that is, diploid (see Figure 2). In the control and ASCUS groups, 6 (8.70\%) and 8 (14.04\%) cases were found to be aneuploid, respectively (see Figure 2). The association of aneuploidy with increasing grades of dysplasia was found to be significant ( $P \leq .001$; Table 1 , see Figure 3 ).

All these cases with aneuploid DNA content and cytologically diagnosed ASCUS and various grades of dysplasia were followed up for 1 year at aforementioned intervals, in order to study the behavior of aneuploid DNA in progression/regression/persistence of disease. Among 57 patients with ASCUS, $49(85.96 \%)$ diploid cases had smears that returned to normal cytology and remaining 8 (14.04\%) aneuploid cases showed signs of progression/regression. One patient presented with HSIL and three with LSIL after one year period of followup. Remaining four aneuploid cases of ASCUS group regressed to normal, as evident from diploid DNA. Out of six aneuploid cases with normal cytological diagnosis, 4 cases were followed, where only one case represented progression of disease from normal to mild dysplasia after a year.

A total of 79 patients who had diagnosis of LSIL, 75 cases were followed up. Out of 39 aneuploid cases, 7 developed moderate dysplasia (CIN II) and 30 cases presented with no change in cytology (CIN I), after a period of six months from the date of registration. All cases showed aneuploid 


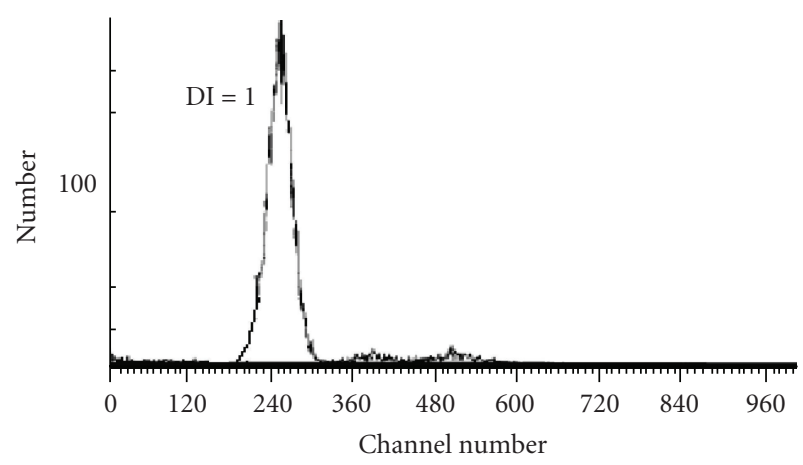

(a)

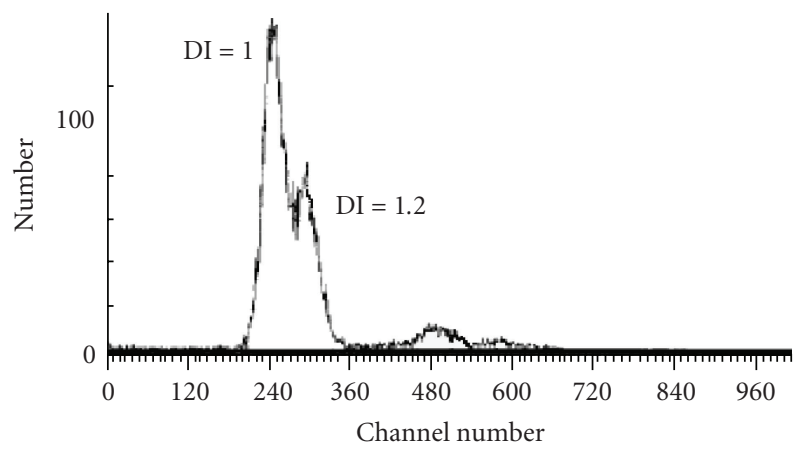

(b)

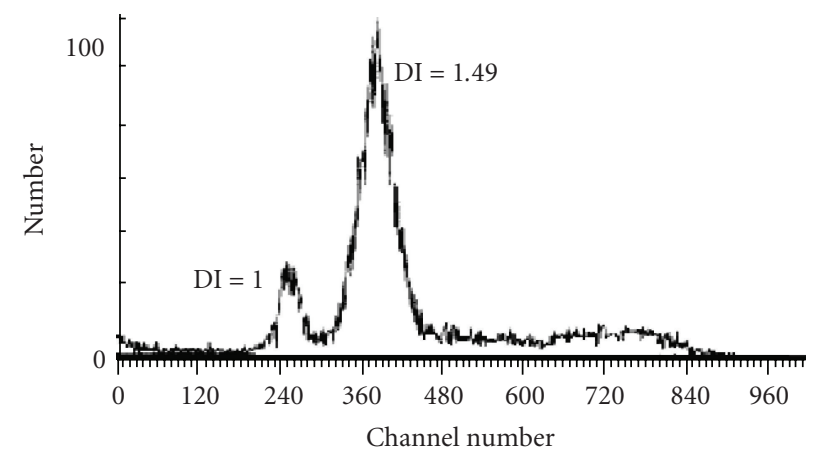

(c)

FIGURE 2: Showing representative histograms of flow-cytometric analysis of DNA contents of cervical smears in different stages of dysplasia. In each sample, 25,000 events were counted at FL2-A following staining with propidium iodide $50 \mu \mathrm{g} / \mathrm{mL}$ for 30 minutes in dark at $4{ }^{\circ} \mathrm{C}$. $Y$ axis showing number of cells and $X$ axis represents DNA ploidy. (a) Showing a diploid peak of DNA. (b) Showing a near diploid aneuploidy. (c) Showing a hyperaneuploidy from severe dysplasia patient. DI shows DNA index.

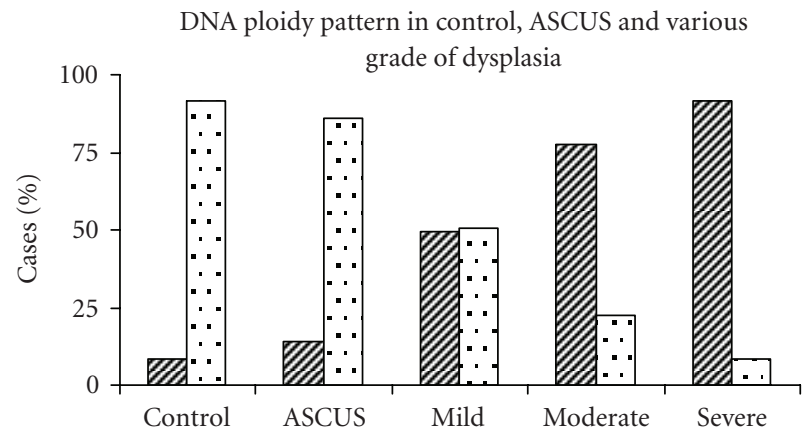

FIGURE 3: Histogram showing percent incidence of anuploidy in control, atypical squamous cells of unknown significance and various grade of dysplasia.

DNA in their followup study. 35 cases who had LSIL with nonaneuploid DNA returned to normal and one patient presented with no change in cytology, that is, remained at CIN I. The sample for this particular subject showed aneuploid DNA content of cell in followup study while 35 normal cases were diploid (Table 2).

Out of 36 cases of moderate dysplasia, only 30 patients were available for followup study and 6 patients underwent hysterectomy. 20 patients out of 25 who were diagnosed with moderate dysplasia (HSIL/CIN II) and with aneuploid
DNA remained CIN II (71.79\%) with an aneuploid DNA in their followup study after three months of registration. In addition, 2 other patients were diagnosed later with CIS, who were positive for aneuploid DNA in their followup. 1 patient with diploid DNA remained at CIN II in cytological followup and other 4 diploid showed a regressive pattern. Out of 11 only 3 aneuploid cases of severe dysplasia (CIN III) were followed, rest underwent prescribed treatment. Of the 3 cases, which were aneuploid, 1 case progressed to CIS and 2 remained at CIN III. The association of aneuploidy with progression of disease was found to be significant (Table 2). $\chi^{2}$ test value for LSIL $(P \leq .001)$ and HSIL $(P \leq .001)$ was significant.

\section{DISCUSSION}

There is evidence that cervical carcinoma evolves on the basis of persistence of aneuploidy [10]. Studies have shown that aneuploid conditions indicate either invasive carcinoma or prospective neoplastic development in cervical dysplasia [18, $19]$ and play a causal role in neoplastic development [20,21].

Genetic abnormalities, such as numerical chromosomal aberrations (aneuploidy and tetraploidy), have been reported in women diagnosed with precancerous and cancerous cervical lesions and are observed frequently in the presence of HPV infections [10, 22, 23]. According to 
TABLE 2: Progression/regression pattern of diploid and aneuploid cases of dysplasia during follow up.

\begin{tabular}{|c|c|c|c|c|c|}
\hline Groups & $\begin{array}{l}\text { Total cases } \\
(n)\end{array}$ & $\begin{array}{c}\text { Ploidy Status } \\
(n)\end{array}$ & $\begin{array}{c}\text { Progression } \\
(n)\end{array}$ & $\begin{array}{c}\text { Regression } \\
(n)\end{array}$ & $\begin{array}{c}\text { Chisquare } \\
\text { value }\end{array}$ \\
\hline Mild & \multirow{2}{*}{75} & Aneuploid (39) & 37 & 2 & \multirow{2}{*}{$63.5^{* *}$} \\
\hline dysplasia & & Diploid (36) & 1 & 35 & \\
\hline Moderate/severe & \multirow{2}{*}{33} & Aneuploid (28) & 25 & 3 & \multirow{2}{*}{$8.4^{*}$} \\
\hline dysplasia & & Diploid (5) & 1 & 4 & \\
\hline
\end{tabular}

${ }^{*} P \leq .01,{ }^{* *} P \leq .001$.

$n$ : Number of cases.

Melsheimer et al. [22], deregulated viral oncogene expression appears to result first in chromosomal instability and aneuploidization and is subsequently followed by integration of HPV genomes in the affected cell clones. In CIN and invasive cervical cancer, DNA ploidy assessment by flow cytometric technique has been established as a prognostic factor that allows the estimation of the relative progressive risk into more advanced lesions [8, 24-27]. Dysplastic epithelium represents potentially precancerous conditions in which the risk of progression to cancer is usually unknown. Bocking and Motherby [28] suggested that the identification of DNA aneuploidy in dysplastic squamous epithelia could increase the predictive value for malignant transformation to over $90 \%$. Similarly, the results of our study have also confirmed the predictive value of aneuploidy with $92 \%$ aneuploid cases in all grades of dysplasia showing progressive pattern of disease (Table 2).

Evidences indicate aberrant DNA content in cells as a cause rather than as a consequence of malignant transformation $[29,30]$. Duesberg et al. pointed out that aneuploid cancers are generally considered to be more dangerous and aggressive than the diploid [31]. Boecking et al. carried out a prospective study to determine the progression to malignancy of cervical smears with ASCUS [32]. Based on "the high prognostic validity of DNA-aneuploidy" researchers concluded that the "aneuploid lesions should immediately be controlled histologically or be removed". In accordance with the above findings, the results of the present study also demonstrate the progressive pattern of disease among aneuploid cases from ASCUS group. Bollmann et al. suggested that ASCUS cases, those with high-risk HPV and with abnormally high DNA content, represent similar biologic features as HSIL with elevated risk to develop cancer [33]. Thus, DNA content may reflect genomic instability of the cells very early in the malignant process, at a point where morphological changes in malignancies or premalignancies are not yet evident [34]. Conceivably, lesions that are defined as nondysplastic, and therefore considered to represent minimal or no risk for developing cancer cervix, may contain readily detectable large-scale genomic alteration viz DNA aneuploidy which could signal a malignant transformation $[34,35]$. The identification of a molecular biomarker of persistent HPV infection in women who had been diagnosed as normal/ASCUS in Pap smear could be a valuable tool in the proper management of this disease. We have also found 6 aneuploid cases from control group and among them, after one-year duration, one case presented the progression of disease.

In this study, we have shown that aneuploid DNA content could be used as a biomarker of progressive cervical changes towards malignancy. Progressive increase in aneuploidy increases the severity of the lesions $(49.36 \%$ for mild dysplasia, $77.77 \%$ for moderate dysplasia versus $91.66 \%$ for severe dysplasia). Our followup results clearly demonstrate that more and more progressive pattern of disease was noted in aneuploid cases and that DNA ploidy could be used as a prognostic marker for cervical malignancies. Comparison of results obtained with Pap screening and DNA ploidy measurement provide a positive correlation between aneuploid DNA and progression of disease (Table 2). Furthermore, the percentage of aneuploid cases towards the progression of disease was higher in followup data that supported the prognostic value of aneuploidy as a marker to identify the progressive behavior of lesion. Occurrence of aneuploidy was exceptional in patients who had samples with morphology that returned to normal, whereas, patients who had cytological signs of disease progression were found with a significantly greater frequency $(P<.01, P<.001$; Table 2$)$. High-grade lesions (according to Bethesda classification) can be detected using cytodiagnosis method with generally good accuracy, but the diagnosis occasionally relies on subjective parameters. Moreover, inadequate sampling may result in a mild morphologic change despite early progressive behavior [36]. Thus, the measurement of DNA content by flow cytometry provides qualitative information and presence of aberrant aneuploid cells in cytological samples, which could serve as a useful parameter along with cytology with good specificity and sensitivity $[37,38]$. If patients at risk could be identified earlier by analysis of parameter that reflects the true biological properties of lesion, treatment regimes could be given selectively to improve the current poor survival rate of cancer cervix cases [39]. Flow cytometric analysis of DNA ploidy may provide a strategic diagnostic tool for early detection of carcinoma cervix $[8,25]$. Therefore, we propose the concept of an HPV screening with reflex cytology in combination with DNA flow cytometry to detect progressive lesions with the greatest possible sensitivity and specificity.

\section{ACKNOWLEDGMENTS}

Authors are thankful to the Ashwani Kumar, (Industrial Toxicology Research Centre, Lucknow, India) for constant encouragement throughout the study. Authors are also 
thankful to Vinita Das and Urmila Singh (Department of Obstetrics and Gynecology, King George's Medical University, Lucknow, India) for taking keen interest in the study. Authors also wish to acknowledge Neeraj Mathur (ITRC) for statistical analysis of the data. Authors are deeply thankful to Indian Council for Medical Research (New Delhi, India) for providing Research Associateship to M. Singh and Senior Research Fellowship to N. Kalra.

\section{REFERENCES}

[1] D. M. Parkin, P. Pisani, and J. Ferlay, "Estimates of the worldwide incidence of eighteen major cancers in 1985," International Journal of Cancer, vol. 54, no. 4, pp. 594-606, 1993.

[2] J. Tiffen and S. M. Mahon, "Cervical cancer: what should we tell women about screening?" Clinical Journal of Oncology Nursing, vol. 10, no. 4, pp. 527-531, 2006.

[3] A. G. Ostor, "Studies on 200 cases of early squamous cell carcinoma of the cervix," International Journal of Gynecological Pathology, vol. 12, no. 3, pp. 193-207, 1993.

[4] K. Lukaszuk, J. Liss, I. Wozniak, J. Emerich, and C. Wójcikowski, "Human papillomavirus type 16 status in cervical carcinoma cell DNA assayed by multiplex PCR," Journal of Clinical Microbiology, vol. 41, no. 2, pp. 608-612, 2003.

[5] H. Z. Hausen, "Papillomavirus infections-a major cause of human cancers," Biochimica et Biophysica Acta, vol. 1288, pp. 55-78, 1996.

[6] M. Schiffman, R. Herrero, A. Hildesheim, et al., "HPV DNA testing in cervical cancer screening: results from women in a high risk province of Costa Rica," Journal of the American Medical Association, vol. 283, no. 1, pp. 87-93, 2000.

[7] M. Schiffman, A. Hildesheim, R. Herrero, and C. Bratti, "Human papillomavirus testing as a screening tool for cervical cancer," The Journal of the American Medical Association, vol. 283, no. 19, pp. 2525-2526, 2000.

[8] P. Melsheimer, R. Klaes, M. von Knebel Doeberitz, and G. Bastert, "Prospective clinical study comparing DNA flow cytometry and HPV typing as predictive tests for persistence and progression of CIN I/II," Communications in Clinical Cytometry, vol. 46, no. 3, pp. 166-171, 2001.

[9] H. zur Hausen, "Human papillomaviruses in the pathogenesis of anogenital cancer," Virology, vol. 184, no. 1, pp. 9-13, 1991.

[10] V. Kashyap and B. C. Das, "DNA aneuploidy and infection of human papillomavirus type 16 in preneoplastic lesions of the uterine cervix: correlation with progression to malignancy," Cancer Letters, vol. 123, no. 1, pp. 47-52, 1998.

[11] N. M. Lonky, M. Sadeghi, G. W. Tsadik, and D. Petitti, "The clinical significance of the poor correlation of cervical dysplasia and cervical malignancy with referral cytologic results," American Journal of Obstetrics and Gynecology, vol. 181, no. 3, pp. 560-566, 1999.

[12] S. C. Cotton, L. Sharp, J. Little, et al., "Trial of management of borderline and other low-grade abnormal smears (TOMBOLA): trial design," Contemporary Clinical Trials, vol. 27, no. 5, pp. 449-471, 2006.

[13] F. Giroud, G. Haroske, A. Reith, and A. Bocking, "ESACP consensus report on diagnostic DNA image cytometry. Part II. Specific recommendations for quality assurance," Analytical Cellular Pathology, vol. 17, pp. 201-208, 1998.
[14] G. Haroske, J. P. A. Baak, H. Danielsen, et al., "Fourth updated ESACP consensus report on diagnostic DNA image cytometry," Analytical Cellular Pathology, vol. 23, no. 2, pp. 89-95, 2001.

[15] D. Solomon, D. Davey, R. Kurman, et al., "The 2001 Bethesda system: terminology for reporting results of cervical cytology," Journal of the American Medical Association, vol. 287, no. 16, pp. 2114-2119, 2002.

[16] I. Nicoletti, G. Migliorati, M. C. Pagliacci, F. Grignani, and C. Riccardi, "A rapid and simple method for measuring thymocyte apoptosis by propidium iodide staining and flow cytometry," Journal of Immunological Methods, vol. 139, no. 2, pp. 271-279, 1991.

[17] P. S. Rabinovitch, "DNA content histogram and cell cycle analysis," Methods in Cell Biology, vol. 41, pp. 263-296, 1994.

[18] V. Kashyap, D. K. Das, and U. K. Luthra, "Microphotometric nuclear DNA analysis in cervical dysplasia of the uterine cervix: its relation to the progression to malignancy and regression to normalcy," Neoplasma, vol. 37 , no. 5, pp. 497500, 1990.

[19] R. Bollmann, M. Bollmann, D. E. Henson, and M. Bodo, "DNA cytometry confirms the utility of the Bethesda system for the classification of Papanicolaou smears," Cancer, vol. 93, no. 3, pp. 222-228, 2001.

[20] T. Webb, "When theories collide: experts develop different models for carcinogenesis," Journal of the National Cancer Institute, vol. 93, no. 2, pp. 92-94, 2001.

[21] A. G. Hanselaar, A. Böcking, H. Gundlach, et al., "Summary statement on quantitative cytochemistry (DNA and molecular biology): task force 8," Acta Cytologica, vol. 45, no. 4, pp. 499501, 2001, International Consensus Conference on the Fight Against Cervical Cancer, IAC Task Force 8 Summary, Chicago, Illinois, USA.

[22] P. Melsheimer, S. Vinokurova, N. Wentzensen, G. Bastert, and M. von Knebel Doeberitz, "DNA aneuploidy and integration of human papillomavirus type $16 \mathrm{E} 6 / \mathrm{E} 7$ oncogenes in intraepithelial neoplasia and invasive squamous cell carcinoma of the cervix uteri," Clinical Cancer Research, vol. 10, no. 9, pp. 30593063, 2004.

[23] A. J. Olaharski and D. A. Eastmond, "Elevated levels of tetraploid cervical cells in human papillomavirus-positive Papanicolaou smears diagnosed as atypical squamous cells of undetermined significance," Cancer, vol. 102, no. 3, pp. 192199, 2004.

[24] M. Anton, R. Nenutil, A. Rejthar, J. Kopocny, B. Ptackova, and J. Zaloudik, "DNA flow cytometry: a predictor of a high-risk group in cervical cancer," Cancer Detection and Prevention, vol. 21, no. 3, pp. 242-246, 1997.

[25] P. Melsheimer, S. Vinokurova, N. Wentzensen, G. Bastert, and M. von Knebel Doeberitz, "DNA aneuploidy and integration of human papillomavirus type $16 \mathrm{E} 6 / \mathrm{E} 7$ oncogenes in intraepithelial neoplasia and invasive squamous cell carcinoma of the cervix uteri," Clinical Cancer Research, vol. 10, no. 9, pp. 30593063, 2004.

[26] R. De Vita, A. Calugi, F. Maggi, F. Mauro, L. Montevecchi, and A. Vecchione, "Flow cytometric DNA analysis of the human cervix affected by human papillomavirus and/or intraepithelial neoplasia," Analytical and Quantitative Cytology and Histology, vol. 12, no. 5, pp. 306-313, 1990.

[27] L.-C. Horn, G. Raptis, and H. Nenning, "DNA cytometric analysis of surgically treated squamous cell cancer of the uterine cervix, stage pT1b1-pT2b," Analytical and Quantitative 
Cytology and Histology, vol. 24, no. 1, pp. 23-29, 2002.

[28] A. Bocking and H. Motherby, "Assessment of cervical dysplasia with DNA image cytometry," Der Pathologe, vol. 20, no. 1, pp. 25-33, 1999.

[29] S. Sen, "Aneuploidy and cancer," Current Opinion in Oncology, vol. 12, no. 1, pp. 82-88, 2000.

[30] J. Sudbo, W. Kildal, B. Risberg, H. S. Koppang, H. E. Danielsen, and A. Reith, "DNA content as a prognostic marker in patients with oral leukoplakia," New England Journal of Medicine, vol. 344, no. 17, pp. 1270-1278, 2001.

[31] P. Duesberg, R. Li, and D. Rasnick, "Aneuploidy approaching a perfect score in predicting and preventing cancer: highlights from a conference held in Oakland in January 2004," Cell Cycle, vol. 3, no. 6, pp. 823-828, 2004.

[32] A. Bocking, F. Giroud, and A. Reith, "Consensus report of the ESACP task force on standardization of diagnostic DNA image cytometry," Analytical Cellular Pathology, vol. 8, no. 1, pp. 6774, 1995.

[33] R. Bollmann, G. Mehes, R. Torka, N. Speich, C. Schmitt, and M. Bollmann, "Determination of features indicating progression in atypical squamous cells with undetermined significance: human papillomavirus typing and DNA ploidy analysis from liquid-based cytologic samples," Cancer, vol. 99, no. 2, pp. 113-117, 2003.

[34] V. Q. Nguyen, H. J. Grote, N. Pomjanski, K. Knops, and A. Bocking, "Interobserver reproducibility of DNA-imagecytometry in ASCUS or higher cervical cytology," Cellular Oncology, vol. 26, no. 3, pp. 143-150, 2004.

[35] A. Bocking and V. Q. Nguyen, "Diagnostic and prognostic use of DNA image cytometry in cervical squamous intraepithelial lesions and invasive carcinoma," Cancer, vol. 102, no. 1, pp. 41-54, 2004.

[36] J. H. Robertson and B. Woodend, "Negative cytology preceding cervical cancer: causes and prevention," Journal of Clinical Pathology, vol. 46, no. 8, pp. 700-702, 1993.

[37] A. Krishan, P. Ganjei-Azar, M. Jorda, R. M. Hamelik, I. M. Reis, and M. Nadji, "Detection of tumor cells in body cavity fluids by flow cytometric and immunocytochemical analysis," Diagnostic Cytopathology, vol. 34, no. 8, pp. 528-541, 2006.

[38] N. U. Kumar, P. Dey, A. K. Mondal, S. K. Singh, and H. Vohra, "DNA flow cytometry and bladder irrigation cytology in detection of bladder carcinoma," Diagnostic Cytopathology, vol. 24, no. 3, pp. 153-156, 2001.

[39] O. Reich, P. Pürstner, P. Klaritsch, J. Haas, M. Lahousen, K. Tamussino, and R. Winter, "Prognostic significance of preoperative DNA flow cytometry in surgically-treated cervical cancer," European Journal of Gynaecological Oncology, vol. 24, no. 1, pp. 13-17, 2003. 


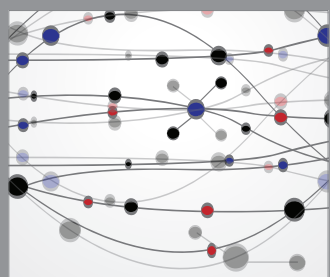

The Scientific World Journal
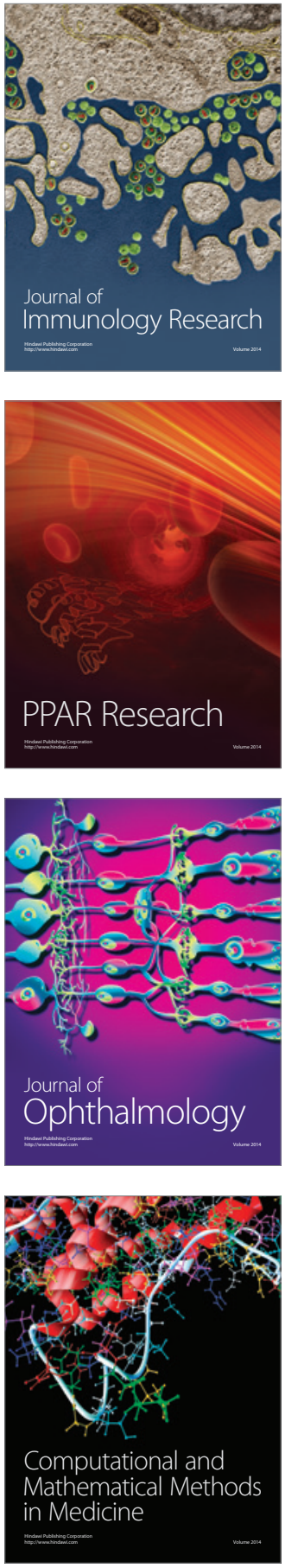

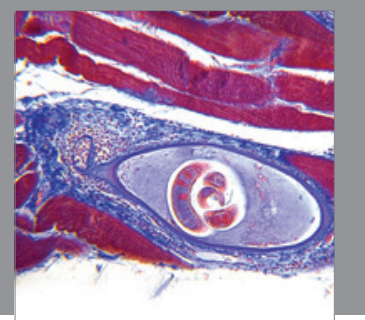

Gastroenterology

Research and Practice
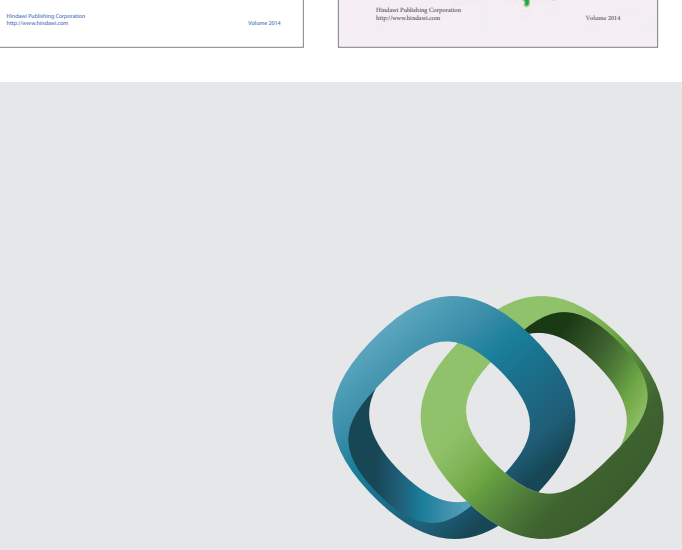

\section{Hindawi}

Submit your manuscripts at

http://www.hindawi.com
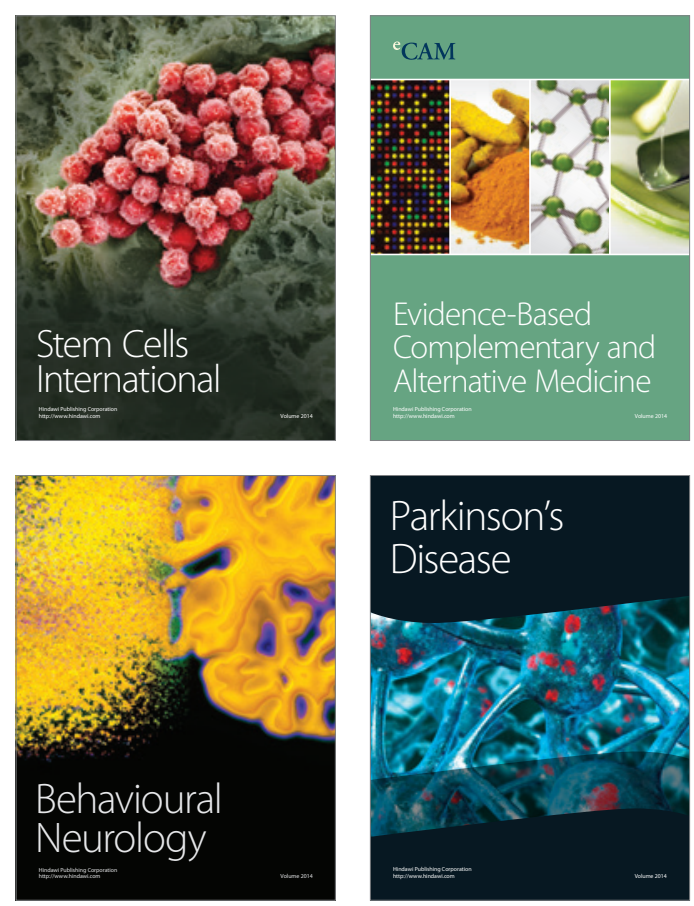

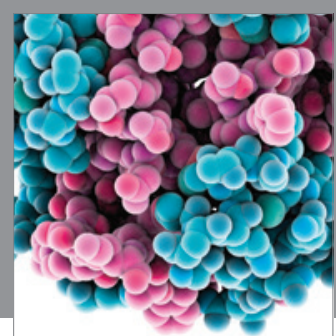

Journal of
Diabetes Research

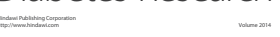

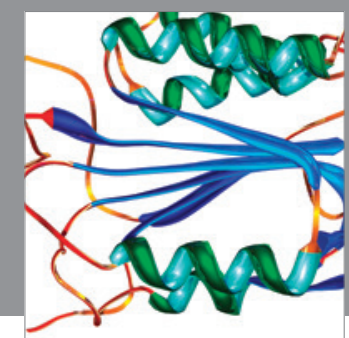

Disease Markers
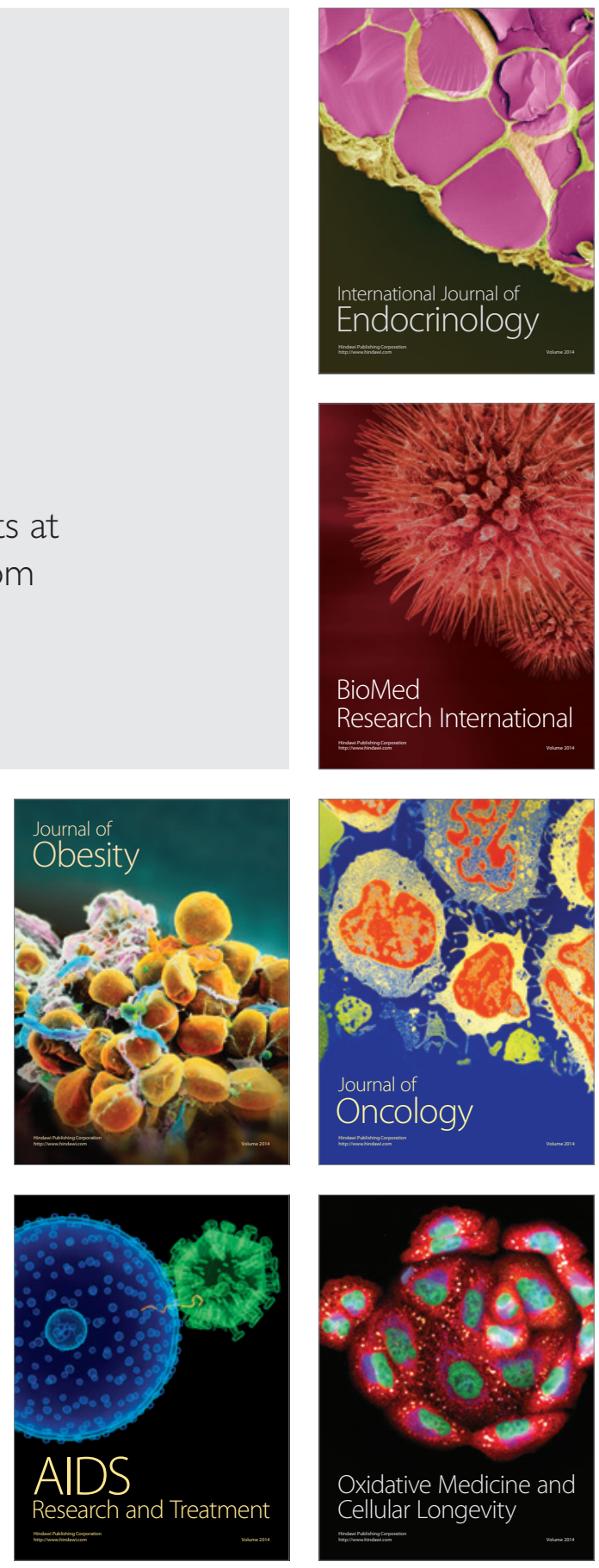